\title{
Year in Review 2019: High-Flow Nasal Cannula Oxygen Therapy for Adult Subjects
}

\author{
Jie Li, Guoqiang Jing, and J Brady Scott
}

\author{
Introduction \\ HFNC Utilization in Various Clinical Conditions \\ Acute Hypoxemic Respiratory Failure \\ Immunocompromised Subjects With Acute Respiratory Failure \\ Postextubation Subjects \\ Planned Extubation and Postsurgery Patients: HFNC Versus $\mathrm{O}_{2}$ Therapy \\ High-Risk Patients: HFNC Versus NIV \\ Preoxygenation Before Intubation: HFNC Versus NIV \\ Breathing Support During Endoscopy \\ COPD \\ COPD Exacerbation \\ Postextubation \\ Stable COPD \\ During Exercise \\ Using ROX Index to Predict HFNC Initiation and Separation Success \\ Other Uses of HFNC: Trans-Nasal Aerosol Pulmonary Delivery \\ Summary
}

\begin{abstract}
Many high-quality clinical trials and meta-analyses on the utilization of high-flow nasal cannula for adult patients have been published in the last 2 years. This review summarizes the recent clinical evidence, with the aim to provide the currently available evidence regarding the utilization of high-flow nasal cannula for the adult patient. Key words: high-flow nasal cannula; oxygen therapy; acute respiratory failure; chronic obstructive pulmonary disease; noninvasive ventilation. [Respir Care 2020;65(4):545-557. (C) 2020 Daedalus Enterprises]
\end{abstract}

\section{Introduction}

High-flow nasal cannula (HFNC) is a relatively new modality of oxygen therapy that delivers warmed, humidified

Dr Li and Mr Scott are affiliated with the Department of Cardiopulmonary Sciences, Division of Respiratory Care, Rush University Medical Center, Chicago, Illinois. Mr Jing is affiliated with the Department of Pulmonary and Critical Care Medicine, Binzhou Medical University Hospital, Binzhou, Shandong, China.

Dr Li presented a version of this paper at the Year in Review 2019 Symposium at AARC Congress 2019, held November 9-12, 2019, in New Orleans, Louisiana. gas at a flow exceeding a patient's inspiratory flow demand. ${ }^{1}$ Since 2018, 20 randomized controlled trials (RCTs) ${ }^{2-21}$ and 10 meta-analyses ${ }^{22-31}$ (Table 1) have been published on HFNC for adult subjects with different clinical conditions. The prediction of HFNC success and aerosol delivery via HFNC have emerged as topics of considerable focus during

Mr Scott discloses relationships with Ventec Life Systems and Teleflex. The other authors have disclosed no conflicts of interest.

Correspondence: Jie Li PhD RRT RRT-ACCS RRT-NPS, $1620 \mathrm{~W}$ Harrison St, Tower LL1202, Chicago, IL 60612.E-mail: jie_li@rush.edu.

DOI: $10.4187 /$ respcare.07663 
this time. Pertinent findings from these recent publications are discussed in this review, and recommendations are made based on the current evidence (Table 2).

\section{HFNC Utilization in Various Clinical Conditions}

\section{Acute Hypoxemic Respiratory Failure}

A known advantage of HFNC is that gas delivered from the device meets or exceeds patient inspiratory flow demand and provides a constant $\mathrm{F}_{\mathrm{IO}_{2}}$. As a result, HFNC has been utilized to treat acute hypoxemic respiratory failure for the past decade. Between 2016 and 2018, 4 metaanalyses have reported its superiority over conventional oxygen therapy and its noninferiority to noninvasive ventilation (NIV) for the improvement of oxygenation and the avoidance of intubation in hypoxemic subjects. ${ }^{28,32-34}$ It should be noted, however, that the number of subjects included in the meta-analyses was $<1,000$. In late 2018, Azoulay et $\mathrm{al}^{18}$ published an RCT that included 776 immunocompromised subjects with acute hypoxemic respiratory failure. Contrary to the findings from the 4 metaanalyses, ${ }^{28,32-34}$ these investigators did not find a significant difference in intubation and mortality between the HFNC and $\mathrm{O}_{2}$ therapy groups. ${ }^{18}$ The large number of the subjects in this study, as well as the contradictory findings, triggered updates to the evidence pertaining to HFNC use in acute hypoxemic respiratory failure. In 2019, Rochwerg et $\mathrm{al}^{22}$ published a systematic review and meta-analysis that included 9 RCTs with 2,093 subjects. They reported that the risk of intubation was found to be lower in subjects treated with HFNC compared to subjects treated with $\mathrm{O}_{2}$ therapy (relative risk $0.85,95 \%$ CI $0.74-0.99$ ), even though there was no difference between hospital mortality, ICU length of stay, and hospital length of stay. ${ }^{22}$ In the meta-analysis by Rochwerg et al, ${ }^{22}$ studies on the use of HFNC for the treatment of postextubation respiratory failure were excluded. Shen et $\mathrm{al}^{29}$ deemed that the exclusion was unnecessary and might cause selection bias. An update on the meta-analysis included 11 RCTs in which the authors noted that the subjects' baseline was an essential factor affecting heterogeneity. In their subgroup analysis that separated subjects on the basis of $\mathrm{P}_{\mathrm{aO}_{2}} / \mathrm{F}_{\mathrm{IO}_{2}}>200 \mathrm{~mm} \mathrm{Hg}$ or $\leq 200 \mathrm{~mm} \mathrm{Hg}$, they reported that subjects with $\mathrm{P}_{\mathrm{aO}_{2}} / \mathrm{F}_{\mathrm{IO}_{2}}$ $>200 \mathrm{~mm} \mathrm{Hg}$, particularly postextubation subjects, had the greatest benefit from HFNC. Additionally, of the 9 RCTs included in the meta-analysis by Rochwerg et al, ${ }^{22} 4$ were completed in emergency department. Tinelli et $\mathrm{al}^{30}$ analyzed these 4 RCTs and observed no significant benefits of HFNC over $\mathrm{O}_{2}$ therapy in subjects with acute hypoxemic respiratory failure in the emergency department. Therefore, future studies are needed to clarify the role of HFNC in subjects with different severity, pathophysiology, and treatment location.
Immunocompromised Subjects With Acute Respiratory Failure. The goals of therapy when treating an immunocompromised patient with acute hypoxemic respiratory failure are to correct hypoxemia and avoid intubation. ${ }^{31}$ HFNC is a reasonable solution for these patients because it is well-tolerated and noninvasive. After the study by Azoulay et $\mathrm{al}^{18}$ was published, several systematic reviews and meta-analyses were completed on the use of HFNC for immunocompromised subjects with acute respiratory failure. ${ }^{23,24,31}$ In the meta-analysis by Cortegiani et al, ${ }^{23}$ they included one retrospective study as well as post hoc analyses from 2 RCTs, in addition to the study by Azoulay et al. ${ }^{18}$ Compared to $\mathrm{O}_{2}$ therapy, HFNC reduced the risk of intubation in immunocompromised subjects in the ICU with acute hypoxemic respiratory failure $(n=1,052$ subjects, odds ratio $0.74,95 \%$ CI $0.55-0.98, P=.03$ ), but HFNC did not reduce the risk of ICU mortality or 28-d mortality. In the meta-analysis published by Kang et al, ${ }^{24}$ even though they included the 4 studies excluded by Cortegiani et al, ${ }^{23}$ their findings supported the superiority of HFNC over $\mathrm{O}_{2}$ therapy to reduce intubation rate. It is noted that they did not find any significant differences between HFNC and NIV, which was in agreement with the recent pairwise and network meta-analysis. ${ }^{31}$ Despite these findings, it should be emphasized that there have been no published RCTs that directly compare HFNC and NIV in immunocompromised patients, and future high-quality RCTs are warranted.

Available evidence suggests that, compared to $\mathrm{O}_{2}$ therapy, HFNC can reduce the risk of intubation for patients with acute hypoxemic respiratory failure, including those who are immunocompromised. However, evidence has not shown a benefit for length of hospital stay or mortality. The benefit of HFNC is more evident for patients with mild hypoxemia $\left(\mathrm{P}_{\mathrm{aO}} / \mathrm{F}_{\mathrm{IO}_{2}}>200 \mathrm{~mm} \mathrm{Hg}\right)$. The evidence that compares HFNC versus NIV as the initial respiratory support for patients with acute hypoxemic respiratory failure is limited, particularly for immunocompromised patients. Future studies that focus on subjects with $\mathrm{P}_{\mathrm{aO}_{2}} / \mathrm{F}_{\mathrm{IO}_{2}} \leq 200 \mathrm{~mm} \mathrm{Hg}$ and comparisons of HFNC and NIV are needed.

\section{Postextubation Subjects}

Planned Extubation and Postsurgery Patients: HFNC Versus $\mathbf{O}_{2}$ Therapy. At the time of extubation, patients are often placed on room air or $\mathrm{O}_{2}$ therapy, if needed. In 2010, Tiruvoipati et $\mathrm{al}^{35}$ initiated the first RCT comparing $1 \mathrm{~h}$ of HFNC at $30 \mathrm{~L} / \mathrm{min}$ to face mask $\mathrm{O}_{2}$ therapy for subjects extubated in the ICU. No differences in gas exchange, breathing frequency, or postextubation respiratory failure were found, although the investigators did note a trend toward improved comfort with HFNC. ${ }^{35}$ Since this RCT was published, others sought to better understand the role of postextubation HFNC. Zhu et $\mathrm{al}^{25}$ published a meta-analysis that compared the use of $\mathrm{HFNC}$ to $\mathrm{O}_{2}$ therapy for 


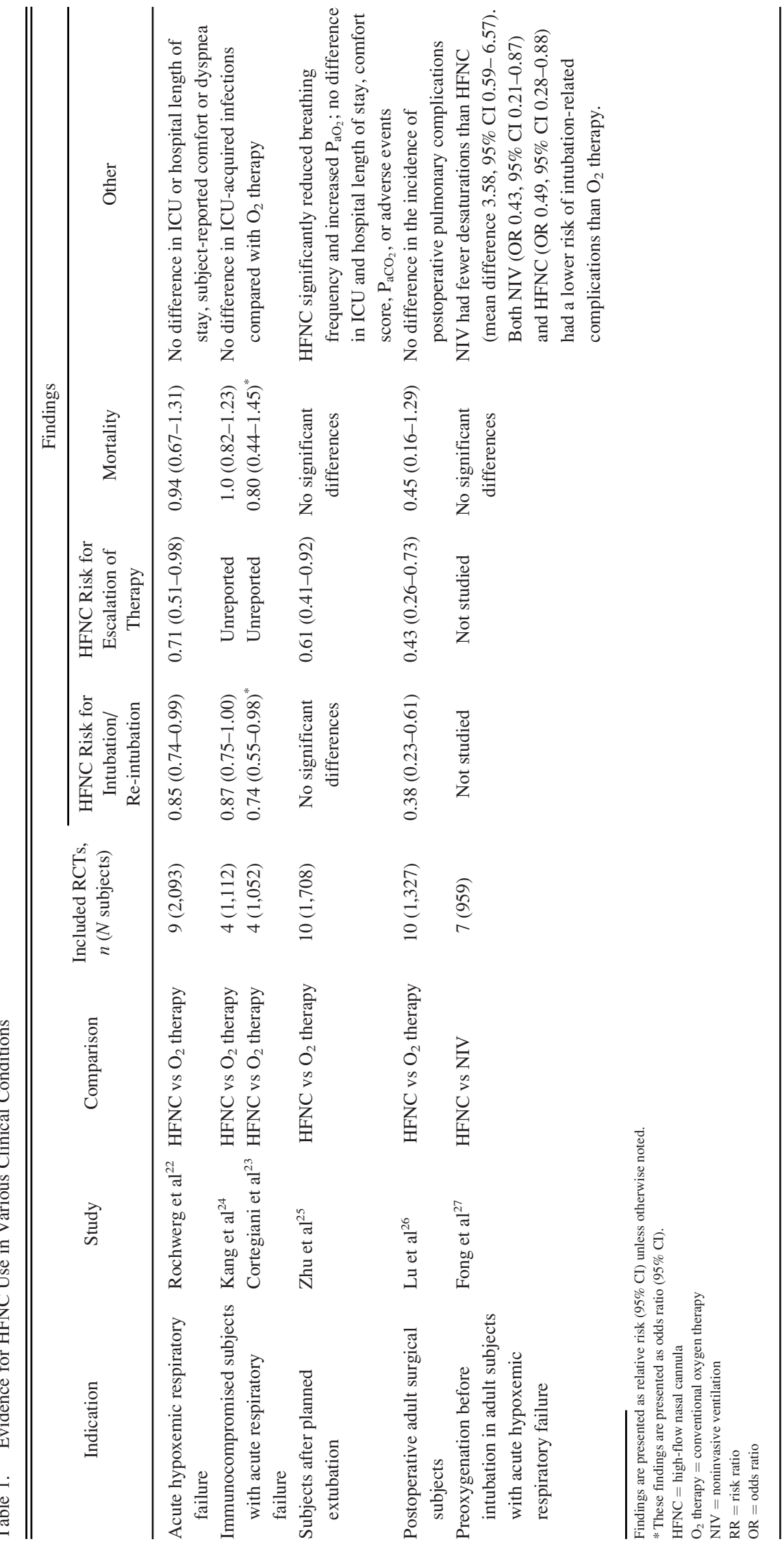


Table 2. Recommendations on the Utilization of HFNC for Different Diseases

\begin{tabular}{|c|c|}
\hline Indication & Take Home Messages \\
\hline Acute hypoxemic respiratory failure & $\begin{array}{l}\text { Compared to } \mathrm{O}_{2} \text { therapy, } \mathrm{HFNC} \text { reduces the risk of intubation, particularly in the } \\
\text { patients with mild hypoxemia }\left(\mathrm{P}_{\mathrm{aO}_{2}} / \mathrm{F}_{\mathrm{IO}_{2}}>200 \mathrm{~mm} \mathrm{Hg}\right)\end{array}$ \\
\hline Immunocompromised patients with acute respiratory failure & Compared to $\mathrm{O}_{2}$ therapy, $\mathrm{HFNC}$ reduces the risk of intubation \\
\hline \multicolumn{2}{|l|}{ Postextubation } \\
\hline $\begin{array}{l}\text { Planned extubation (low-risk patients): } \mathrm{HFNC} \text { vs } \mathrm{O}_{2} \\
\text { therapy }\end{array}$ & $\begin{array}{l}\text { Compared to } \mathrm{O}_{2} \text { therapy, } \mathrm{HFNC} \text { reduces the risk of developing postextubation failure } \\
\text { but does not decrease re-intubation rate }\end{array}$ \\
\hline Postsurgery patients: HFNC vs $\mathrm{O}_{2}$ therapy & Controversial \\
\hline High-risk patients: HFNC vs NIV & $\begin{array}{l}\text { Compared to the use of HFNC or NIV alone, use of NIV for } 48 \mathrm{~h} \text { and HFNC use in the } \\
\text { NIV break might reduce re-intubation rate }\end{array}$ \\
\hline Preoxygenation before intubation: HFNC vs NIV & $\begin{array}{l}\text { HFNC is superior to } \mathrm{O}_{2} \text { therapy (but inferior to NIV) in avoiding intubation-related } \\
\text { complications. Using a resuscitator bag or critical care ventilator to preoxygenate } \\
\text { patients before intubation might be more cost-effective }\end{array}$ \\
\hline Breathing support during endoscopy & Effectiveness of preventing hypoxia during endoscopy: NIV $>\mathrm{HFNC}>\mathrm{O}_{2}$ therapy \\
\hline \multicolumn{2}{|l|}{ COPD } \\
\hline Stable COPD & $\begin{array}{l}\text { Long-term ( } \geq 6 \mathrm{wk} \text { ) use of HFNC can improve } \mathrm{CO}_{2} \text { retention for patients with stable } \\
\text { hypercapnic COPD, improve quality of life, and reduce COPD exacerbations }\end{array}$ \\
\hline During exercise & HFNC may improve exercise endurance time if $\mathrm{S}_{\mathrm{pO}_{2}}$ is maintained $>90 \%$ \\
\hline COPD exacerbation & $\begin{array}{l}\text { HFNC may be considered as an alternative to NIV in mild to moderate COPD, but } \\
\text { more robust evidence is warranted }\end{array}$ \\
\hline Postextubation & $\begin{array}{l}\text { HFNC may be considered as an alternative to NIV to facilitate weaning patients with } \\
\text { COPD and stable hypercapnia from invasive ventilation, although more robust evi- } \\
\text { dence is warranted }\end{array}$ \\
\hline
\end{tabular}

HFNC $=$ high-flow nasal cannula

$\mathrm{O}_{2}$ therapy = conventional oxygen therapy

NIV $=$ noninvasive ventilation

subjects after planned extubation. Seven RCTs and 3 crossover RCTs were included, with 1,708 subjects enrolled. Five of the RCTs indicated that HFNC reduced the risk of the development of respiratory failure after extubation (relative risk $0.61,95 \%$ CI $0.41-0.92, P=.02$ ). However, HFNC did not reduce the risk of re-intubation in the 7 RCTs. It is important to note that the heterogeneity of the studies included in the meta-analysis was of concern. As such, the authors performed subgroup analyses on the HFNC duration ( $\geq 24 \mathrm{~h}$ vs $<24 \mathrm{~h}$ ), gas flow ( $\geq 40$ $\mathrm{L} / \mathrm{min}$ vs $<40 \mathrm{~L} / \mathrm{min}$ ), disease severity, and hypercapnia versus non-hypercapnia; they found no significant interaction between HFNC versus $\mathrm{O}_{2}$ therapy. ${ }^{25}$ Also, only about one third of the subjects with postextubation respiratory failure in either group were re-intubated (HFNC: 48 of 136 per 1,000 subjects; $\mathrm{O}_{2}$ therapy: 82 of 219 per 1,000 subjects). ${ }^{25}$ This may imply the importance of the timely escalation of therapy, such as switching from $\mathrm{O}_{2}$ therapy to HFNC/NIV or from HFNC to NIV in an effort to avoid re-intubation.

After this meta-analysis, 4 new RCTs on postsurgery subjects were published. ${ }^{2,4,8,17}$ For post-cardiac surgery subjects, compared to $\mathrm{O}_{2}$ therapy, the prophylactic use of HFNC after extubation was reported to improve oxygenation and reduce the need for NIV. ${ }^{2}$ HFNC was also reported to reduce the ICU readmission and hospital length of stay in this population. ${ }^{17}$ For obese subjects who underwent bariatric surgery, compared to $\mathrm{O}_{2}$ therapy, the use of HFNC immediately after extubation significantly improved oxygenation within $3 \mathrm{~h}$ and reduced pulmonary complications during hospitalization. ${ }^{4}$ These results are contradictory to previous studies in subjects with abdominal surgery ${ }^{36}$ and obese subjects with cardiac surgery, ${ }^{37}$ which did not indicate any significant difference between HFNC and $\mathrm{O}_{2}$ therapy on all outcomes. For subjects who underwent lung resection, there was no significant difference of postoperative hypoxemia, respiratory failure, or pulmonary complications between HFNC and air-entrainment mask groups. ${ }^{8}$ These findings are also contradictory to the results of a study that compared HFNC with $\mathrm{O}_{2}$ therapy for subjects after thoracoscopic lobectomy, in which HFNC was shown to reduce the risk of re-intubation. ${ }^{38}$ Future studies on the use of HFNC for postsurgical subjects with considerations regarding specific type of surgery and outcomes are needed.

High-Risk Patients: HFNC Versus NIV. In 2016, Hernández et $\mathrm{al}^{39}$ published the first multicenter RCT to compare the use of HFNC versus NIV in subjects who had one or more high risk factors for extubation failure. No significant differences of re-intubation rates were noted between HFNC 
YeAR IN REVIEW 2019: HFNC FOR AdULTS

Table 3. Comparisons of 2 RCTs on Postextubation Subjects With High Risk for Extubation Failure

\begin{tabular}{|c|c|c|c|c|c|c|}
\hline & \multicolumn{3}{|c|}{ Hernández et al ${ }^{39}$} & \multicolumn{3}{|c|}{ Thille et $\mathrm{al}^{11}$} \\
\hline & HFNC & NIV & $P$ & HFNC & $\mathrm{NIV}+\mathrm{HFNC}$ & $P$ \\
\hline Subjects, $n$ & 290 & 314 & ND & 302 & 339 & ND \\
\hline $\begin{array}{l}\text { Underlying chronic lung disease, } \\
n(\%)\end{array}$ & $54(18.6)$ & $70(22.3)$ & ND & $87(29)$ & $126(37)$ & ND \\
\hline $\begin{array}{l}\text { Duration of mechanical } \\
\text { ventilation before extubation, } \\
\text { h, median (IQR) }\end{array}$ & $4(2-9)$ & $4(2-8)$ & ND & $5(3-9)$ & $6(3-11)$ & ND \\
\hline Respiratory primary failure, $n(\%)$ & 98 (33.8) & $121(38.5)$ & ND & $158(52)$ & 167 (49) & ND \\
\hline Settings & $50 \pm 5 \mathrm{~L} / \mathrm{min}$ & $\begin{array}{l}\text { To achieve } \mathrm{V}_{\mathrm{T}}=8 \mathrm{~mL} / \mathrm{kg} \\
\mathrm{f}=25 \text { breaths } / \mathrm{min}\end{array}$ & ND & $50 \pm 5 \mathrm{~L} / \mathrm{min}$ & $\begin{array}{l}\text { Pressure support } 7.8 \pm 2.5 \mathrm{~cm} \\
\quad \mathrm{H}_{2} \mathrm{O} \text { PEEP } 5.3 \pm 1.1 \mathrm{~cm} \mathrm{H}_{2} \mathrm{O}\end{array}$ & ND \\
\hline $\begin{array}{l}\text { Length of utilization, } h \text {, median } \\
\text { (IQR) }\end{array}$ & 24 & $14(8-23)$ in the first $24 \mathrm{~h}$ & ND & $\begin{array}{l}42 \pm 11 \mathrm{~h} \text { in } \\
\text { the first } 48 \mathrm{~h}\end{array}$ & NIV $22 \pm 9 \mathrm{~h}$ in the first $48 \mathrm{~h}$ & ND \\
\hline $\begin{array}{l}\text { Postextubation respiratory failure, } \\
n(\%)\end{array}$ & $78(26.9)$ & $125(39.8)$ & $<.001$ & $88(29)$ & $70(21)$ & .01 \\
\hline $\begin{array}{l}\text { All-cause re-intubation within } \\
72 \mathrm{~h}, n(\%)\end{array}$ & $66(22.8)$ & $60(19.1)$ & .27 & $47(16)$ & $30(9)$ & .009 \\
\hline Re-intubation within 24 h, $n(\%)$ & $30(10.3)$ & $35(11.1)$ & .75 & $26(8.6)$ & $18(5.3)$ & .10 \\
\hline Re-intubation within 48 h, $n(\%)$ & $56(19.3)$ & $45(14.3)$ & .10 & $36(12)$ & $24(7)$ & .04 \\
\hline $\begin{array}{l}\text { Respiratory-caused re-intubation, } \\
n(\%)\end{array}$ & $49(16.9)$ & $50(15.9)$ & .75 & $46(15)$ & $42(12)$ & .30 \\
\hline $\begin{array}{l}\text { Time to re-intubation, } \mathrm{h} \text {, median } \\
\text { (IQR) }\end{array}$ & $26.5(14-39)$ & $21.5(10-47)$ & ND & $39(12-67)$ & $33(7-81)$ & .76 \\
\hline $\begin{array}{l}\text { RCT }=\text { randomized controlled trial } \\
\text { HFNC = high-flow nasal cannula } \\
\text { NIV = noninvasive ventilation } \\
\text { ND }=\text { no data } \\
\text { IQR = interquartile range } \\
V_{\mathrm{T}}=\text { tidal volume } \\
\mathrm{f}=\text { breathing frequency }\end{array}$ & & & & & & \\
\hline
\end{tabular}

and NIV, however, the incidence of postextubation failure was higher in the NIV group $(39.8 \%$ vs $26.9 \%, P<.001)$. In contrast, Thille et $\mathrm{al}^{11}$ completed a multicenter RCT on a similar subject population in 2019 and reported a lower incidence of postextubation respiratory failure $(21 \%$ vs $29 \%, P=.01)$ and re-intubation rate (9\% vs $16 \%, P=$ .009) in the NIV group compared to the HFNC group. The opposing results from these 2 similar studies might be due to the way NIV was utilized (Table 3). In the study by Hernández et al, ${ }^{39}$ the actual duration of NIV use was only 14 (8-23) h out of $24 \mathrm{~h}$. In the study by Thille et al, ${ }^{11} \mathrm{NIV}$ was used for $22 \pm 9 \mathrm{~h}$ out of $48 \mathrm{~h}$; in addition, HFNC was used during breaks from NIV, whereas Hernández et $\mathrm{al}^{39}$ utilized $\mathrm{O}_{2}$ therapy. Spoletini et $\mathrm{al}^{16}$ reported that the use of HFNC instead of $\mathrm{O}_{2}$ therapy during NIV breaks improved subject comfort and reduced the incidence of dyspnea. This might explain why the incidence of postextubation respiratory failure in NIV group was higher in the study by Hernández et $\mathrm{al}^{39}$ than the study by Thille et $\mathrm{al}^{11}$ (39.8\% vs $21 \%$ ). Admittedly, it is difficult to tell which factor (ie, extended use of NIV or HFNC use during NIV break), if any, played a key role in the outcome. Additionally, when comparing the 2 studies, it is important to note the duration of HFNC use. With similar flow settings (50 $\pm 5 \mathrm{~L} / \mathrm{min})$, the re-intubation rate in both studies was similar within 24 $\mathrm{h}$ postextubation in the HFNC groups (10.3\% vs $8.6 \%)$. However, HFNC therapy was withdrawn after $24 \mathrm{~h}$ in the study by Hernández et al, ${ }^{39}$ and the re-intubation rate was nearly doubled at $48 \mathrm{~h}$ in HFNC group. In contrast, there was only a slight increase in the re-intubation rate in the Thille et al $^{11}$ study, which continued the use of HFNC for 48 h. $^{1}$

In all, for patients who are to be routinely extubated or at low risk of re-intubation, HFNC may reduce the risk of developing postextubation respiratory failure compared to $\mathrm{O}_{2}$ therapy. However, this does not imply that clinicians need to use HFNC for all patients who are to be extubated because the incidence of postextubation respiratory failure and re-intubation is already low in this population. The prophylactic use of HFNC in patients at lowrisk for extubation failure may be a significant waste of resources. The use of HFNC for postsurgical patients remains controversial. Future studies in this population are needed, with an emphasis on type of surgery and specific 


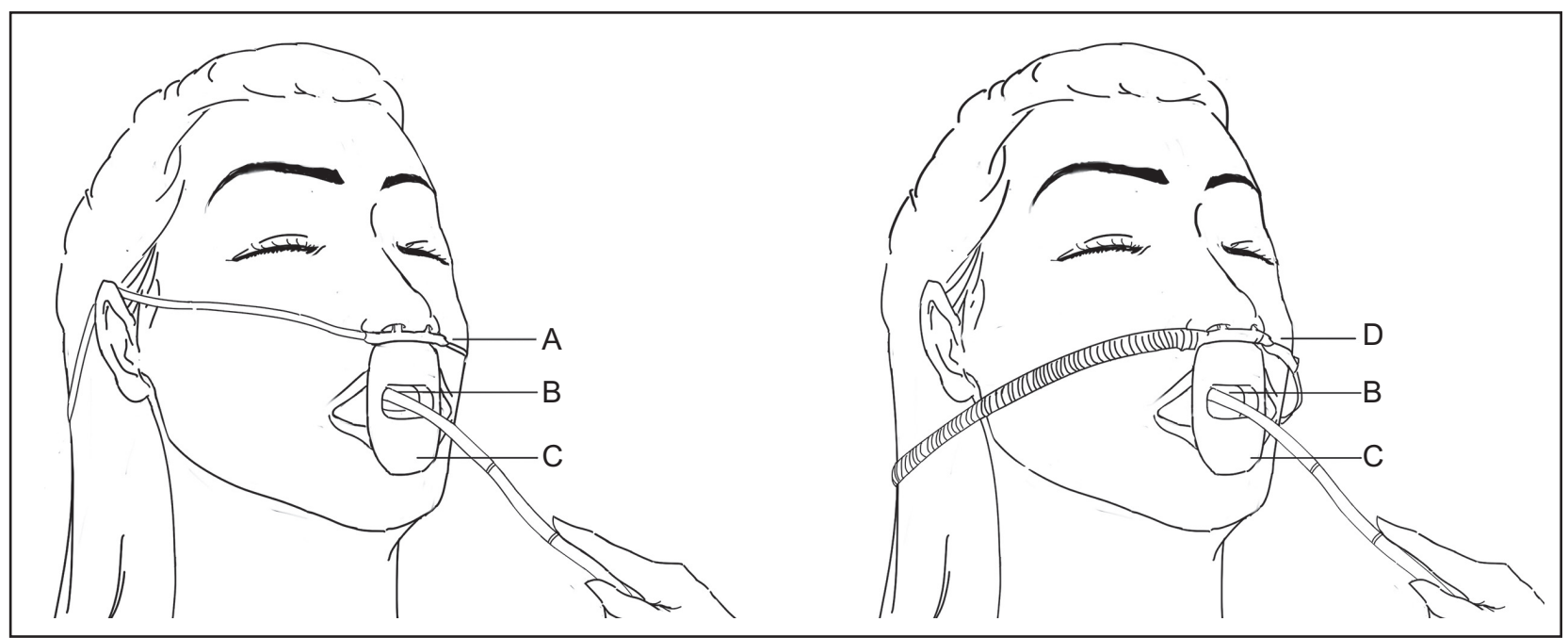

Fig. 1. Using high-flow nasal cannula (HFNC) and conventional nasal cannula during endoscopy examination: (A) conventional nasal cannula; (B) endoscopy; (C) bite block; (D) HFNC. Modified from Reference 14.

outcomes (eg, postoperative hypoxemia, prevention of respiratory failure, development of pulmonary complications). Compared to the prophylactic use of HFNC for all patients, it might be wise to identify those patients who are at risk for developing respiratory failure after extubation using $\mathrm{O}_{2}$ therapy. Identification of the appropriate time to escalate treatments, such as the switch from $\mathrm{O}_{2}$ therapy to $\mathrm{HFNC/}$ NIV or switch from HFNC to NIV to avoid re-intubation is also needed. Similarly, for patients who are at high risk for re-intubation after extubation, the use of NIV for all patients is also unnecessary. Future studies on identifying the correct patients and the correct timing for postextubation NIV are still warranted. Finally, the duration of HFNC/NIV use and the use of HFNC during breaks from NIV may play a vital role for those patients at risk for extubation failure, but more studies are needed.

\section{Preoxygenation Before Intubation: HFNC Versus NIV}

A recent meta-analysis demonstrated that preoxygenation with HFNC prior to intubation in adult subjects with hypoxemia reduced the risk of intubation-related complications compared to $\mathrm{O}_{2}$ therapy. However, when compared to NIV, subjects treated with HFNC had more desaturation (Table 1). ${ }^{27}$ Interestingly, all 7 of the RCTs using HFNC to preoxygenate subjects before intubation were completed in Europe, with 6 of them in France. It appears that the clinicians in Europe, particularly in France, are more familiar with the process of using HFNC to preoxygenate patients prior to intubation compared to clinicians in other areas of the world. In a recent nationwide survey among French ICU physicians, unsurprisingly, $84 \%$ of them agreed that use of HFNC to preoxygenate patients before intubation was a good use of the modality. ${ }^{40}$ Clinically, the duration of preparing acute hypoxemic patients for intubation is short and usually takes no more than $10 \mathrm{~min}$. If patients are not already being treated with HFNC therapy, the time to set up the device may be unnecessary, especially considering the financial cost. There are several other measures available at the bedside, such as a manual resuscitator (with a PEEP valve) or a critical care ventilator (with mask), which could maintain higher mean airway pressure and better ventilation compared to HFNC. The manual resuscitator would already be needed for patients who are heavily sedated or paralyzed before and after intubation. Intubation-related complications and cost-effectiveness studies are needed in the future to compare the use of HFNC versus manual resuscitator/ventilator to preoxygenate patients for intubation.

\section{Breathing Support During Endoscopy}

There has been an increasing interest in the use of HFNC for oxygen therapy during endoscopy recently (Fig. 1), with 4 RCTs published on this topic in 2019. In total, there have been 6 RCTs completed, with 3 during bronchoscopy and 3 during esophagogastroduodenoscopy (Table 4). ${ }^{7,10,13-15,41}$ HFNC has been reported to be less effective than NIV ${ }^{10,13,41}$ but to be superior to $\mathrm{O}_{2}$ therapy ${ }^{7,14,15}$ in maintaining oxygenation during endoscopic examination. In the 3 RCTs with nonhypoxemic subjects, it should be noted that the $\mathrm{HFNC} \mathrm{F}_{\mathrm{IO}_{2}}$ was set at 1.0 with flow at $30-60 \mathrm{~L} / \mathrm{min}$. This is compared to oxygen flow at $2-10 \mathrm{~L} / \mathrm{min}$ using a regular nasal cannula. ${ }^{7,14,15}$ Considering the higher oxygen flows utilized during HFNC, the lower incidence of hypoxia in HFNC group was expected. In contrast, Riccio et al ${ }^{13}$ reported that, if the $\mathrm{F}_{\mathrm{IO}_{2}}$ for subjects in HFNC group was set at $0.36-0.4$, similar to the $\mathrm{F}_{\mathrm{IO}_{2}}$ used by the subjects in the control group (nasal cannula 4 


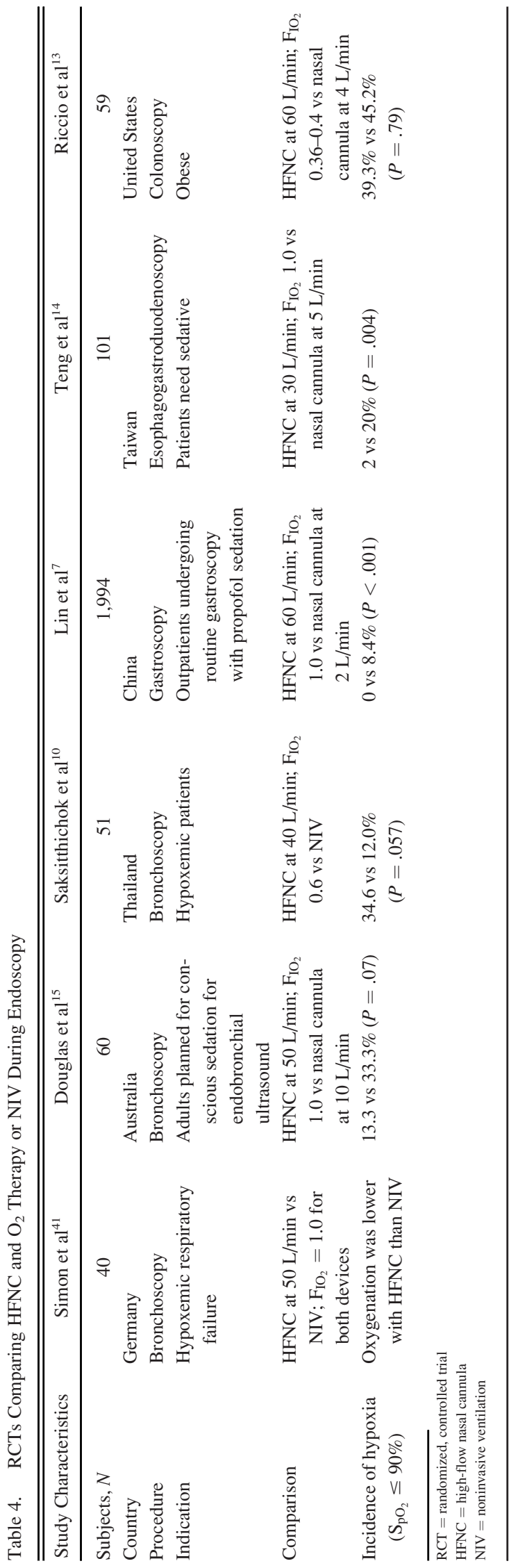

$\mathrm{L} / \mathrm{min}$ ), the incidence of hypoxia was similar in both HFNC and regular nasal cannula groups during colonoscopy despite an HFNC flow of $60 \mathrm{~L} / \mathrm{min}(39.3 \%$ vs $45.2 \%, P=$ .79). This finding, with the aforementioned studies, ${ }^{7,14,15}$ provides evidence that HFNC can reduce the incidence of hypoxia when a high $\mathrm{F}_{\mathrm{IO}_{2}}$ (1.0) and high flow are used together. In the largest study ( $N=1,994$ subjects), only $8.4 \%$ of subjects undergoing gastroscopy experienced hypoxia in the nasal cannula group with a flow of $2 \mathrm{~L} / \mathrm{min}$ oxygen. ${ }^{7}$ Considering the cost-effectiveness of using HFNC during endoscopy, it may be unnecessary to use HFNC for all patients, and it might be worthwhile to reserve its use for high-risk patients, such as those with hypoxemia or hypercapnia. ${ }^{10,41}$ Future studies are needed to identify the patients who benefit from HFNC during endoscopy.

\section{COPD}

In the past, HFNC was thought to improve oxygenation whereas NIV was thought to improve ventilation and oxygenation. Because of this, NIV has been more commonly used to treat patients with COPD due to the need for ventilatory support. Recently, physiologic studies have reported that HFNC can reduce $\mathrm{CO}_{2}$ due to the effects of washing out dead space, prompting an increased interest in the use of HFNC for COPD patients. ${ }^{42-45}$ In 2019, Pisani et $\mathrm{al}^{46}$ published a systematic review on the utilization of HFNC for COPD exacerbation. HFNC has also been evaluated for postextubation support of subjects with COPD, for longterm domiciliary use, and for facilitating exercise for subjects with stable COPD.

COPD Exacerbation. There has been only 1 RCT published on the utilization of HFNC during COPD exacerbations. ${ }^{47}$ The quality of the study is of concern, due to the fact that $19 \%$ of subjects dropped out and the ambiguity of the study design. In total, 88 subjects were enrolled for final analysis, and no significant difference was noted between the HFNC and NIV groups regarding intubation rate and 30-d hospital mortality. Also, the arterial blood gases after 6 and $24 \mathrm{~h}$ of utilization were not significantly different between the 2 groups. ${ }^{47}$ This finding was similar to a recent observational cohort study comparing HFNC with NIV for COPD with acute to moderate hypercapnic respiratory failure. In that study, the authors reported a similar incidence of treatment failure between the 2 groups. ${ }^{48}$ They also reported fewer incidences of skin breakdown and nursing interventions in HFNC group (Table 5). ${ }^{48}$ In a crossover physiological study, Longhini et al ${ }^{49}$ enrolled 30 subjects with COPD exacerbation who had used NIV for $>24 \mathrm{~h}$. Five 30-min trials were designed; $\mathrm{HFNC}$ and $\mathrm{O}_{2}$ therapy were randomly assigned in the second and fourth trials, and NIV was utilized in the other 3 trials. Diaphragm thickening fraction increased significantly during the $\mathrm{O}_{2}$ therapy 
YeAR IN REVIEW 2019: HFNC FOR AdULTS

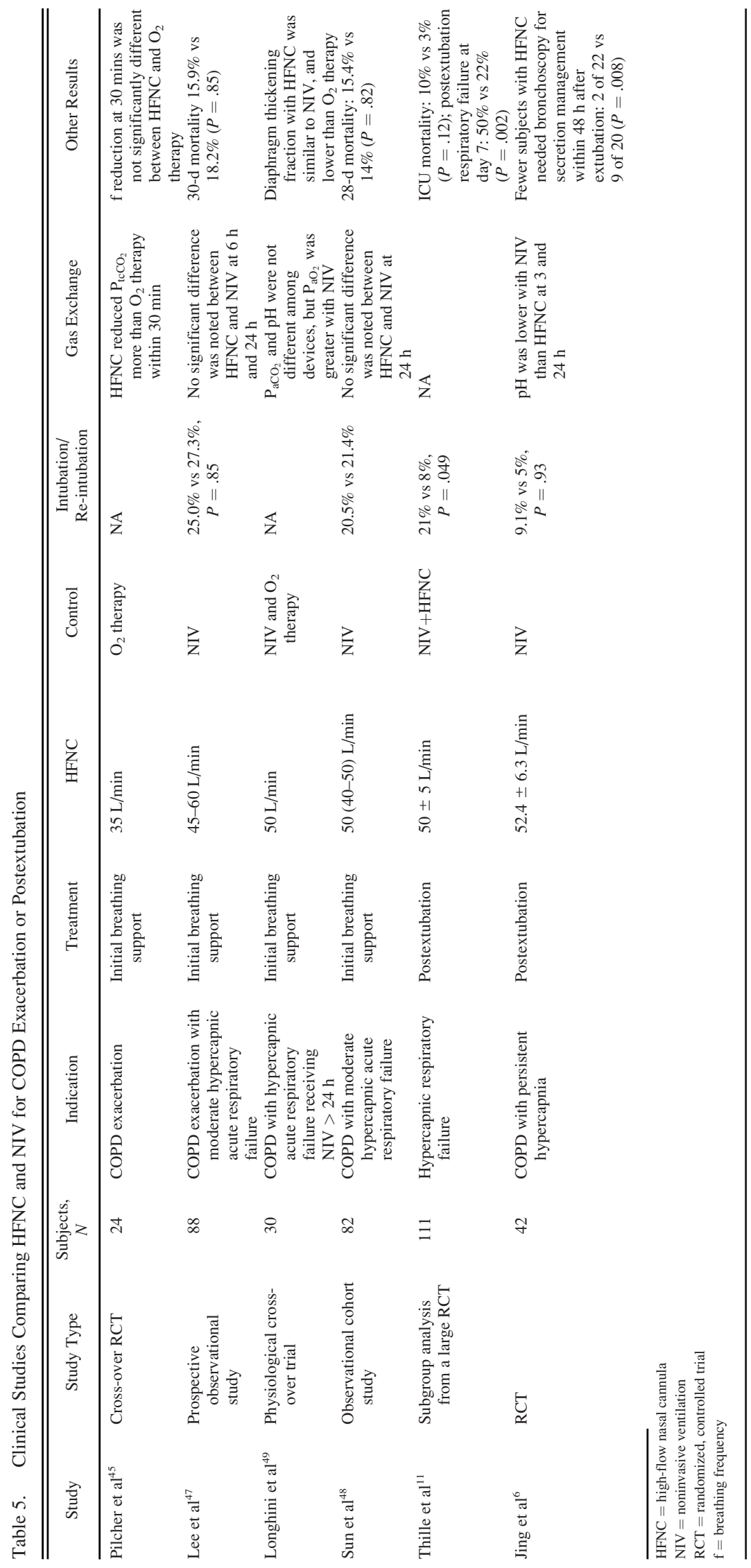


trial, whereas it remained unchanged during the HFNC trial. ${ }^{49}$ This promising finding may support HFNC as alternative to NIV in mild to moderate COPD patients, although more high-quality studies are warranted before making conclusion. Cortegiani et $\mathrm{al}^{50}$ are currently conducting an RCT to compare the use of HFNC and NIV for exacerbations of COPD with mild to moderate hypercapnic acute respiratory failure. This trial may provide important insight in the role of HFNC for mild to moderate exacerbations of COPD.

Postextubation. In the large multi-center RCT by Thille et $\mathrm{al}^{11}$ that compared HFNC with NIV+HFNC, 111 of the 641 subjects had hypercapnic respiratory failure, and the cumulative re-intubation rate at day 7 was higher in the group treated by HFNC alone (Table 5). It should be emphasized that HFNC therapy was only utilized for $48 \mathrm{~h}$, and the cumulative re-intubation rate at $48 \mathrm{~h}$ was not significantly different between the 2 groups ( $8 \%$ vs $3 \%, P=.23$ ). ${ }^{11}$ If HFNC was used for longer periods of time, it is plausible that the re-intubation rate at day 7 would have been different. Jing et $\mathrm{al}^{6}$ published an RCT that enrolled 42 subjects with COPD who had hypercapnia at extubation. The authors reported no significant difference in the rate of re-intubation between HFNC and NIV. ${ }^{6}$ They also noted that fewer subjects in HFNC group required bronchoscopy for secretion management within $48 \mathrm{~h}$ after extubation ( 2 out of 22 vs 9 out of 20, $P=.008){ }^{6}$ The evidence to support HFNC in this population based on this study is relatively weak due to the small sample size. Future studies with larger sample sizes are needed to generate more conclusive evidence.

Stable COPD. In 2010, Rea et $\mathrm{al}^{51}$ compared the use of 12 months of $\mathrm{HFNC}$ versus $\mathrm{O}_{2}$ therapy for 60 subjects with stable COPD or bronchiectasis. Even though the average duration of HFNC was only $1.6 \mathrm{~h} / \mathrm{d}$, HFNC was associated with a reduction of COPD exacerbation frequency and days when compared to $\mathrm{O}_{2}$ therapy (Table 6). Additionally, a cost analysis showed that HFNC was a moderately costeffective measure for moderate to severe COPD or bronchiectasis. ${ }^{52}$ In 2018, Storgaard et $\mathrm{al}^{21}$ reported that the use of HFNC for $6 \mathrm{~h} / \mathrm{d}$ for 12 months significantly reduced COPD exacerbations (3.12 vs 4.95/subject annually, $P<$ .001 ) and improved quality of life. In the 2 short-term cross-over RCTs with 6 weeks of HFNC versus 6 weeks of $\mathrm{O}_{2}$ therapy or NIV, HFNC was noted to be superior over $\mathrm{O}_{2}$ therapy in improving $\mathrm{CO}_{2}$ retention and quality of life, ${ }^{53}$ whereas it was noninferior to NIV on improving $\mathrm{CO}_{2}$ retention. ${ }^{3}$

During Exercise. In 2016, Cirio et $\mathrm{al}^{54}$ implemented a cross-over RCT to compare HFNC with air-entrainment mask at the same $\mathrm{F}_{\mathrm{IO}_{2}}$ for 12 subjects with stable severe COPD during constant loading tests. The authors reported higher oxygen saturations with HFNC at 55-60 L/min than

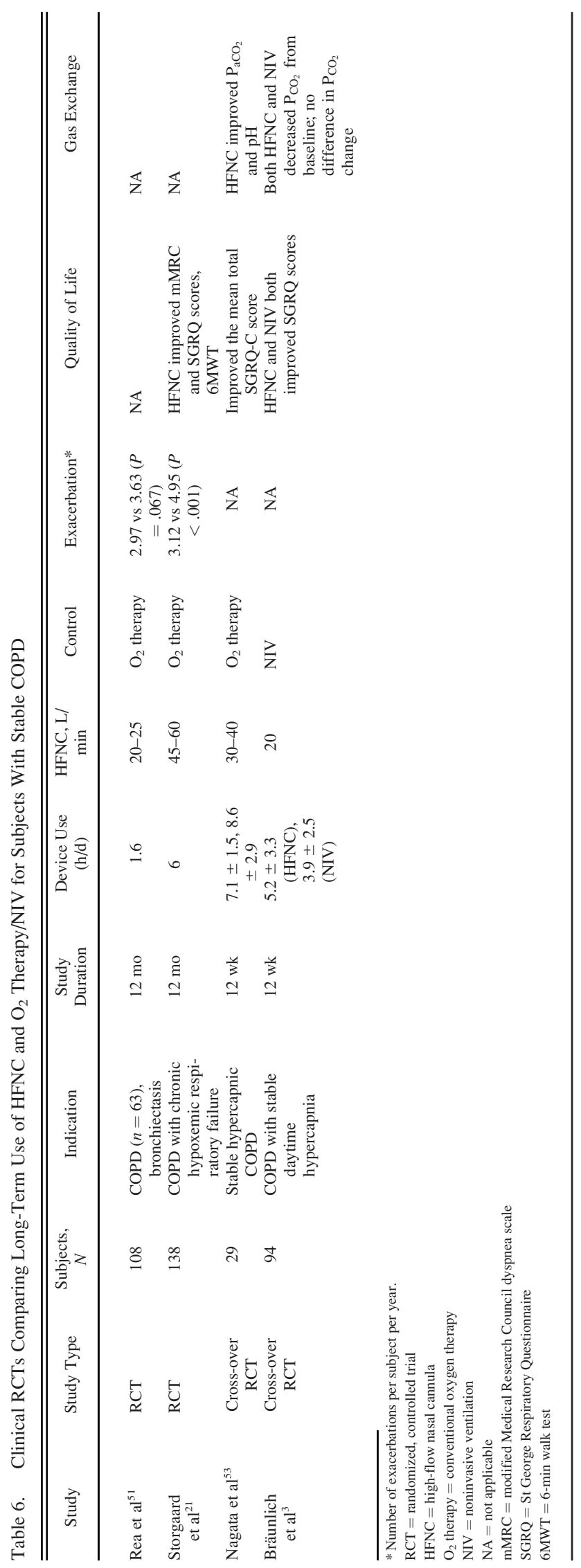


with the air-entrainment mask $(95 \pm 3 \%$ vs $89 \pm 3 \%$, respectively, $P<.005$ ), and endurance time was increased by $41 \pm 36 \%$ with HFNC. ${ }^{54}$ In 2019 , Prieur et al ${ }^{9}$ published a similar study that enrolled 19 subjects with severe to very severe COPD following exacerbation. The study participants used either HFNC or $\mathrm{O}_{2}$ therapy during constant work-rate exercises. The authors reported that there were no improvements in endurance time or symptoms, such as dyspnea and leg discomfort, with HFNC utilization. ${ }^{9}$ They did note, however, that transcutaneously measured partial pressure of carbon dioxide and heart rate during exercises were lower in the HFNC group than in the group receiving $\mathrm{O}_{2}$ therapy. ${ }^{9}$ The main differences between these 2 studies were the oxygen device in the control group and the $\mathrm{S}_{\mathrm{pO}_{2}}$ goal during exercises. In the study by Cirio et al, ${ }^{54}$ an air-entrainment mask was utilized with the same $\mathrm{F}_{\mathrm{IO}_{2}}$ as HFNC. However, because the $\mathrm{S}_{\mathrm{pO}_{2}}$ was lower in the air-entrainment mask group than in the HFNC group at 55-60 L/min during exercise, ${ }^{54}$ it suggests that the actual $\mathrm{F}_{\mathrm{IO}_{2}}$ was lower due to the air entrainment during exercises due to increased inspiratory flow demand by the subject. ${ }^{55,56}$ In contrast, Prieur et $\mathrm{al}^{9}$ allowed for flow titration when a standard nasal cannula was utilized in the control group, with a titration goal of $\mathrm{S}_{\mathrm{pO}_{2}} \geq 90 \%$ during exercise. ${ }^{9}$ As such, desaturation during exercise might explain the reduced endurance time in the control group in the study by Cirio et al. ${ }^{54}$ Interestingly, Prieur et $\mathrm{al}^{9}$ reported a trend toward lower endurance time in the HFNC group. The authors hypothesized that HFNC therapy at $60 \mathrm{~L} / \mathrm{min}$ in their study might cause dynamic hyperinflation, ${ }^{9}$ which could ultimately limit exercise endurance; this hypothesis still requires more physiological studies to confirm.

\section{Using ROX Index to Predict HFNC Initiation and Separation Success}

Little attention was paid to the prediction of the success of HFNC initiation and separation until 2016. Roca et $\mathrm{al}^{57}$ introduced the concept of using an index that combines oxygenation and breathing frequency to predict HFNC success. They enrolled 157 subjects with severe pneumonia treated with $\mathrm{HFNC}$ at 2 centers in the 4-y prospective cohort study. ${ }^{57}$ The ratio of $\mathrm{S}_{\mathrm{pO}_{2}} / \mathrm{F}_{\mathrm{IO}_{2}}$ to breathing frequency, known as the ROX index, was used to predict the need to switch from HFNC to mechanical ventilation. By using the Cox proportional hazards model, Roca et $\mathrm{al}^{57}$ reported that the cutoff point of the ROX index was 4.88 at $12 \mathrm{~h}$ of HFNC. This suggests that a ROX index $>4.88$ after being treated with HFNC for $12 \mathrm{~h}$ might indicate a higher possibility of HFNC success. ${ }^{57}$ After the study was published, the investigators organized a multi-center observational cohort study with a larger sample size to validate their findings. ${ }^{58}$ In addition to the consistency of ROX >
4.88 to predict HFNC success, they further explored the cutoff values for ROX to predict HFNC failure after 2, 6, and $12 \mathrm{~h}$ of HFNC treatment. They observed that HFNC failure was likely if the ROX index was $>2.85,3.47$, or 3.85 at 2,6 , and $12 \mathrm{~h}$, respectively. ${ }^{58}$ Similarly, Zemach et $\mathrm{al}^{59}$ reported that an increased ROX index was the only independent predictor of HFNC success in their multivariate analysis. This suggests that patients with a low ROX index or with little incremental change of ROX index over time might need earlier and more frequent interventions. Future clinical studies with deliberate treatment algorithms guided by the ROX index are needed. With regard to weaning and liberation from HFNC, Rodriguez et $\mathrm{al}^{60}$ investigated the ROX index to predict successful separation from HFNC in a retrospective study. They reported that HFNC was successfully removed from $88 \%$ (168 out of 190) of subjects in their study at the first attempt, and a $\mathrm{F}_{\mathrm{IO}_{2}} \leq 0.4$ and ROX $\geq 9.2$ were predictive of HFNC separation success. ${ }^{60}$

An important consideration regarding the ROX index is that it is affected by the HFNC gas flow. When gas flow was increased from 30 to $60 \mathrm{~L} / \mathrm{min}$ in the study by Mauri et $\mathrm{al},{ }^{61} 70 \%$ of the ROX indexes increased while the remaining subjects had an unchanged or decreased ROX index. Modifications to a typical HFNC setup may also affect oxygenation. Duprez et $\mathrm{al}^{62}$ reported that placing a doubletrunk mask over the HFNC nasal prongs in an attempt to reduce room air entrainment can improve oxygenation. In 15 different subjects with acute refractory hypoxemia, with flows set at $51 \pm 6 \mathrm{~L} / \mathrm{min}, \mathrm{P}_{\mathrm{aO}}$ improved from $68 \pm$ $14 \mathrm{~mm} \mathrm{Hg}$ to $85 \pm 22 \mathrm{~mm} \mathrm{Hg}(P<.001)$ after adding the double-trunk mask. ${ }^{62}$ These findings might indicate the need to modify the ROX index by gas flow or modifications to a typical setup.

\section{Other Uses of HFNC: Trans-Nasal Aerosol Pulmonary Delivery}

Removing HFNC to deliver traditional aerosol therapy reduces the benefits of HFNC. Placing a face mask with nebulizer over the HFNC may result in the substantial reduction of the intended inhaled dose. ${ }^{63}$ As such, placing a nebulizer in-line with HFNC has become a delivery route of interest. ${ }^{64,65}$ Concerns have been raised about the inhaled dose via the trans-nasal aerosol delivery method. Two recently published cross-over RCTs reported that albuterol delivery at regular flow settings $(30-35 \mathrm{~L} / \mathrm{min})$ for subjects with stable COPD and asthma could generate similar bronchodilation responses as a jet nebulizer with a mouthpiece/mask. ${ }^{19,20} \mathrm{Li}$ et $\mathrm{al}^{66}$ further explored the dose-response relationship among 42 subjects with stable COPD and asthma. In their study, the investigators reported that $1.5 \mathrm{mg}$ albuterol delivered via HFNC at 15 $20 \mathrm{~L} / \mathrm{min}$ elicited similar bronchodilation effects as 400 


\section{YEAR IN REVIEW 2019: HFNC FOR ADULTS}

$\mu \mathrm{g}$ albuterol via pressurized metered-dose inhaler and spacer. ${ }^{66}$

For patients who need to inhale aerosolized medication continuously for long periods of time (ie, $>2 \mathrm{~h}$ ), such as inhaled albuterol for those with severe asthma ${ }^{67}$ or inhaled epoprostenol for patients with pulmonary hypertension, ${ }^{68,69,70}$ traditional aerosol delivery such as jet nebulizer via mask/mouthpiece is challenging. Continuous transnasal aerosol delivery via HFNC offers a feasible solution to reduce the inconvenience and discomfort associated with traditional aerosol delivery setups. Two retrospective studies reported improvement in oxygenation when inhaled epoprostenol was delivered via HFNC. ${ }^{68,69}$ Titrating flow to be lower than subject inspiratory flow was found to generate more evident responses of inhaled epoprostenol than using constant flow. ${ }^{70}$ However, the evidence to support the use of continuous aerosol delivery via HFNC is still weak due to the retrospective nature and small sample size of these studies. Also, the overall safety of delivering pulmonary vasodilators via the nasal route warrants more investigation.

\section{Summary}

There have been many advances in the utilization of HFNC therapy for adult patients in the past 2 years. Results from high-quality RCTs support the use of HFNC therapy for patients with acute hypoxemic respiratory failure and patients with planned extubation compared to $\mathrm{O}_{2}$ therapy. $\mathrm{HFNC}$ is also favorable for long-term use for patients with hypercapnic COPD. Evidence also supports the use of HFNC during endoscopy and for preoxygenation before intubation. However, cost-effectiveness still needs to be considered in both of these applications. There is also some emerging evidence that supports the combined use of NIV and HFNC to facilitate weaning patients at high risk for extubation failure. The ROX index may be a useful tool to predict the successful initiation or separation of HFNC, but further studies are needed. Evidence for the use of HFNC for postsurgical patients and for patients with severe COPD during exercise remains controversial and also warrant more studies. There are currently no guidelines regarding the use of HFNC for various disease states, but, due to the widespread use, there is an apparent need.

\section{REFERENCES}

1. Nishimura M. High-flow nasal cannula oxygen therapy in adults: physiological benefits, indication, clinical benefits, and adverse effects. Respir Care 2016;61(4):529-541.

2. Vourc'h M, Nicolet J, Volteau C, Caubert L, Chabbert C, Lepoivre T, et al. High-flow therapy by nasal cannulae versus high-flow face mask in severe hypoxemia after cardiac surgery: a single-center randomized controlled study-the heart flow study. J Cardiothorac Vasc Anesth 2020;34(1):157-165.
3. Bräunlich J, Dellweg D, Bastian A, Budweiser S, Randerath W, Triché $\mathrm{D}$, et al. Nasal high-flow versus noninvasive ventilation in patients with chronic hypercapnic COPD. Int J Chron Obstruct Pulmon Dis 2019;14:1411-1421.

4. Ferrando C, Puig J, Serralta F, Carrizo J, Pozo N, Arocas B, et al. High-flow nasal cannula oxygenation reduces postoperative hypoxemia in morbidly obese patients: a randomized controlled trial. Minerva Anestesiol 2019;85(10):1062-1070.

5. Frat JP, Ricard JD, Quenot JP, Pichon N, Demoule A, Forel JM, et al. Non-invasive ventilation versus high-flow nasal cannula oxygen therapy with apnoeic oxygenation for preoxygenation before intubation of patients with acute hypoxaemic respiratory failure: a randomised, multicentre, open-label trial. Lancet Respir Med 2019;7(4):303-312.

6. Jing G, Li J, Hao D, Wang T, Sun Y, Tian H, et al. Comparison of high flow nasal cannula with noninvasive ventilation in chronic obstructive pulmonary disease patients with hypercapnia in preventing postextubation respiratory failure: a pilot randomized controlled trial. Res Nurs Health 2019;42(3):217-225.

7. Lin Y, Zhang X, Li L, Wei M, Zhao B, Wang X, et al. High-flow nasal cannula oxygen therapy and hypoxia during gastroscopy with propofol sedation: a randomized multicenter clinical trial. Gastrointest Endosc 2019;90(4):591-601.

8. Pennisi MA, Bello G, Congedo MT, Montini L, Nachira D, Ferretti GM, et al. Early nasal high-flow versus venturi mask oxygen therapy after lung resection: a randomized trial. Crit Care 2019;23(1):68.

9. Prieur G, Medrinal C, Combret Y, Dupuis Lozeron E, Bonnevie T, Gravier FE, et al. Nasal high flow does not improve exercise tolerance in COPD patients recovering from acute exacerbation: a randomized crossover study. Respirology 2019;24(11):1088-1094.

10. Saksitthichok B, Petnak T, So-Ngern A, Boonsarngsuk V. A prospective randomized comparative study of high-flow nasal cannula oxygen and non-invasive ventilation in hypoxemic patients undergoing diagnostic flexible bronchoscopy. J Thorac Dis 2019;11(5):1929-1939.

11. Thille AW, Muller G, Gacouin A, Coudroy R, Decavele M, Sonneville R, et al. Effect of postextubation high-flow nasal oxygen with noninvasive ventilation vs high-flow nasal oxygen alone on reintubation among patients at high risk of extubation failure: a randomized clinical trial. JAMA 2019;322(15):1465-1475.

12. Vourc'h M, Baud G, Feuillet F, Blanchard C, Mirallie E, Guitton C, et al. High-flow nasal cannulae versus non-invasive ventilation for preoxygenation of obese patients: the PREOPTIPOP randomized trial. EClinicalMedicine 2019;13:112-119.

13. Riccio CA, Sarmiento S, Minhajuddin A, Nasir D, Fox AA. High-flow versus standard nasal cannula in morbidly obese patients during colonoscopy: a prospective, randomized clinical trial. J Clin Anesth 2019; 54:19-24.

14. Teng WN, Ting CK, Wang YT, Hou MC, Chang WK, Tsou MY, et al. High-flow nasal cannula and mandibular advancement bite block decrease hypoxic events during sedative esophagogastroduodenoscopy: a randomized clinical trial. Biomed Res Int 2019;2019: 4206795.

15. Douglas N, Ng I, Nazeem F, Lee K, Mezzavia P, Krieser R, et al. A randomised controlled trial comparing high-flow nasal oxygen with standard management for conscious sedation during bronchoscopy. Anaesthesia 2018;73(2):169-176.

16. Spoletini G, Mega C, Pisani L, Alotaibi M, Khoja A, Price LL, et al. High-flow nasal therapy vs standard oxygen during breaks off noninvasive ventilation for acute respiratory failure: a pilot randomized controlled trial. J Crit Care 2018;48:418-425.

17. Zochios V, Collier T, Blaudszun G, Butchart A, Earwaker M, Jones N, Klein AA. The effect of high-flow nasal oxygen on hospital length of stay in cardiac surgical patients at high risk for respiratory complications: a randomised controlled trial. Anaesthesia 2018;73(12):14781488 . 


\section{YEAR IN REVIEW 2019: HFNC FOR ADULTS}

18. Azoulay E, Lemiale V, Mokart D, Nseir S, Argaud L, Pène F, et al. Effect of high-flow nasal oxygen vs standard oxygen on 28-day mortality in immunocompromised patients with acute respiratory failure: the HIGH randomized clinical trial. JAMA 2018;320(20):2099-2107.

19. Bräunlich J, Wirtz H. Oral versus nasal high-flow bronchodilator inhalation in chronic obstructive pulmonary disease. J Aerosol Med Pulm Drug Deliv 2018;31(4):248-254.

20. Reminiac F, Vecellio L, Bodet-Contentin L, Gissot V, Le Pennec D, Salmon GC, et al. Nasal high-flow bronchodilator nebulization: a randomized cross-over study. Ann Intensive Care 2018;8(1):128.

21. Storgaard LH, Hockey HU, Laursen BS, Weinreich UM. Long-term effects of oxygen-enriched high-flow nasal cannula treatment in COPD patients with chronic hypoxemic respiratory failure. Int $\mathrm{J}$ Chron Obstruct Pulmon Dis 2018;13:1195-1205.

22. Rochwerg B, Granton D, Wang DX, Helviz Y, Einav S, Frat JP, et al. High flow nasal cannula compared with conventional oxygen therapy for acute hypoxemic respiratory failure: a systematic review and metaanalysis. Intensive Care Med 2019;45(5):563-572.

23. Cortegiani A, Crimi C, Sanfilippo F, Noto A, Di Falco D, Grasselli G, et al. High flow nasal therapy in immunocompromised patients with acute respiratory failure: a systematic review and meta-analysis. J Crit Care 2019;50:250-256.

24. Kang H, Zhao Z, Tong Z. Effect of high-flow nasal cannula oxygen therapy in immunocompromised subjects with acute respiratory failure. Respir Care 2019 [Epub ahead of print].

25. Zhu Y, Yin H, Zhang R, Ye X, Wei J. High-flow nasal cannula oxygen therapy versus conventional oxygen therapy in patients after planned extubation: a systematic review and meta-analysis. Crit Care 2019;23 (1): 180 .

26. Lu Z, Chang W, Meng SS, Zhang X, Xie J, Xu JY, et al. Effect of high-flow nasal cannula oxygen therapy compared with conventional oxygen therapy in postoperative patients: a systematic review and meta-analysis. BMJ Open 2019;9(8):e027523.

27. Fong $\mathrm{KM}, \mathrm{Au} \mathrm{SY}, \mathrm{Ng}$ G. Preoxygenation before intubation in adult patients with acute hypoxemic respiratory failure: a network metaanalysis of randomized trials. Crit Care 2019;23(1):319.

28. Huang HW, Sun XM, Shi ZH, Chen GQ, Chen L, Friedrich JO, Zhou JX. Effect of high-flow nasal cannula oxygen therapy versus conventional oxygen therapy and noninvasive ventilation on reintubation rate in adult patients after extubation: a systematic review and meta-analysis of randomized controlled trials. J Intensive Care Med 2018;33 (11):609-623.

29. Shen Y, Cai G, Yan J. Effect of high flow nasal cannula therapy may be modified by $\mathrm{PaO} 2 / \mathrm{FIO} 2$ ratio in acute hypoxemic respiratory failure. Intensive Care Med 2019;45(8):1169-1170.

30. Tinelli V, Cabrini L, Fominskiy E, Franchini S, Ferrante L, Ball L, et al. High flow nasal cannula oxygen vs. conventional oxygen therapy and noninvasive ventilation in emergency department patients: a systematic review and meta-analysis. J Emerg Med 2019;57(3):322-328.

31. Zayed Y, Banifadel M, Barbarawi M, Kheiri B, Chahine A, Rashdan $\mathrm{L}$, et al. Noninvasive oxygenation strategies in immunocompromised patients with acute hypoxemic respiratory failure: a pairwise and network meta-analysis of randomized controlled trials. J Intensive Care Med 2019 [Epub ahead of print].

32. Ni YN, Luo J, Yu H, Liu D, Ni Z, Cheng J, et al. Can high-flow nasal cannula reduce the rate of endotracheal intubation in adult patients with acute respiratory failure compared with conventional oxygen therapy and noninvasive positive pressure ventilation? A systematic review and meta-analysis. Chest 2017;151(4):764-775.

33. Maitra S, Som A, Bhattacharjee S, Arora MK, Baidya DK. Comparison of high-flow nasal oxygen therapy with conventional oxygen therapy and noninvasive ventilation in adult patients with acute hypoxemic respiratory failure: a meta-analysis and systematic review. J Crit Care 2016;35:138-144.
34. Lee CC, Mankodi D, Shaharyar S, Ravindranathan S, Danckers M, Herscovici P, et al. High flow nasal cannula versus conventional oxygen therapy and non-invasive ventilation in adults with acute hypoxemic respiratory failure: a systematic review. Respir Med 2016;121: 100-108.

35. Tiruvoipati R, Lewis D, Haji K, Botha J. High-flow nasal oxygen vs high-flow face mask: a randomized crossover trial in extubated patients. J Crit Care 2010;25(3):463-468.

36. Futier E, Paugam-Burtz C, Godet T, Khoy-Ear L, Rozencwajg S, Delay JM, et al. Effect of early postextubation high-flow nasal cannula vs conventional oxygen therapy on hypoxaemia in patients after major abdominal surgery: a French multicentre randomised controlled trial (OPERA). Intensive Care Med 2016;42(12):1888-1898.

37. Corley A, Bull T, Spooner AJ, Barnett AG, Fraser JF. Direct extubation onto high-flow nasal cannulae post-cardiac surgery versus standard treatment in patients with a $\mathrm{BMI} \geq 30$ : a randomised controlled trial. Intensive Care Med 2015;41(5):887-894.

38. Yu Y, Qian X, Liu C, Zhu C. Effect of high-flow nasal cannula versus conventional oxygen therapy for patients with thoracoscopic lobectomy after extubation. Can Respir J 2017;2017:7894631.

39. Hernández G, Vaquero C, Colinas L, Cuena R, González P, Canabal A, et al. Effect of postextubation high-flow nasal cannula vs noninvasive ventilation on reintubation and postextubation respiratory failure in high-risk patients: a randomized clinical trial. JAMA 2016;316 (15):1565-1574.

40. Besnier E, Hobeika S, NSeir S, Lambiotte F, Du Cheyron D, Sauneuf $\mathrm{B}$, et al. High-flow nasal cannula therapy: clinical practice in intensive care units. Ann Intensive Care 2019;9(1):98.

41. Simon M, Braune S, Frings D, Wiontzek AK, Klose H, Kluge S. High-flow nasal cannula oxygen versus non-invasive ventilation in patients with acute hypoxaemic respiratory failure undergoing flexible bronchoscopy: a prospective randomised trial. Crit Care 2014;18 (6):712.

42. Fraser JF, Spooner AJ, Dunster KR, Anstey CM, Corley A. Nasal high flow oxygen therapy in patients with COPD reduces respiratory rate and tissue carbon dioxide while increasing tidal and end-expiratory lung volumes: a randomised crossover trial. Thorax 2016;71(8):759761.

43. Pisani L, Fasano L, Corcione N, Comellini V, Musti MA, Brandao M, et al. Change in pulmonary mechanics and the effect on breathing pattern of high flow oxygen therapy in stable hypercapnic COPD. Thorax 2017;72(4):373-375.

44. Biselli P, Fricke K, Grote L, Braun AT, Kirkness J, Smith P, et al. Reductions in dead space ventilation with nasal high flow depend on physiological dead space volume: metabolic hood measurements during sleep in patients with COPD and controls. Eur Respir J 2018;51 (5): 1702251.

45. Pilcher J, Eastlake L, Richards M, Power S, Cripps T, Bibby S, et al. Physiological effects of titrated oxygen via nasal high-flow cannulae in COPD exacerbations: a randomized controlled cross-over trial. Respirology 2017;22(6):1149-1155.

46. Pisani L, Astuto M, Prediletto I, Longhini F. High flow through nasal cannula in exacerbated COPD patients: a systematic review. Pulmonology 2019;25(6):348-354.

47. Lee MK, Choi J, Park B, Kim B, Lee SJ, Kim SH, et al. High flow nasal cannulae oxygen therapy in acute-moderate hypercapnic respiratory failure. Clin Respir J 2018;12(6):2046-2056.

48. Sun J, Li Y, Ling B, Zhu Q, Hu Y, Tan D, et al. High flow nasal cannula oxygen therapy versus non-invasive ventilation for chronic obstructive pulmonary disease with acute-moderate hypercapnic respiratory failure: an observational cohort study. Int $\mathrm{J}$ Chron Obstruct Pulmon Dis 2019;14:1229-1237.

49. Longhini F, Pisani L, Lungu R, Comellini V, Bruni A, Garofalo E, et al. High-flow oxygen therapy after noninvasive ventilation 


\section{YEAR IN REVIEW 2019: HFNC FOR ADULTS}

interruption in patients recovering from hypercapnic acute respiratory failure: a physiological crossover trial. Crit Care Med 2019;47(6): e506-e511.

50. Cortegiani A, Longhini F, Carlucci A, Scala R, Groff P, Bruni A, et al. High-flow nasal therapy versus noninvasive ventilation in COPD patients with mild-to-moderate hypercapnic acute respiratory failure: study protocol for a noninferiority randomized clinical trial. Trials 2019;20(1):450.

51. Rea H, McAuley S, Jayaram L, Garrett J, Hockey H, Storey L, et al. The clinical utility of long-term humidification therapy in chronic airway disease. Respir Med 2010;104(4):525-533.

52. Milne RJ, Hockey H, Rea H. Long-term air humidification therapy is cost-effective for patients with moderate or severe chronic obstructive pulmonary disease or bronchiectasis. Value Health 2014;17(4):320327.

53. Nagata K, Kikuchi T, Horie T, Shiraki A, Kitajima T, Kadowaki T, et al. Domiciliary high-flow nasal cannula oxygen therapy for patients with stable hypercapnic chronic obstructive pulmonary disease: a multicenter randomized crossover trial. Ann Am Thorac Soc 2018;15 (4):432-439.

54. Cirio S, Piran M, Vitacca M, Piaggi G, Ceriana P, Prazzoli M, et al. Effects of heated and humidified high flow gases during high-intensity constant-load exercise on severe COPD patients with ventilatory limitation. Respir Med 2016;118:128-132.

55. Ritchie JE, Williams AB, Gerard C, Hockey H. Evaluation of a humidified nasal high-flow oxygen system, using oxygraphy, capnography and measurement of upper airway pressures. Anaesth Intensive Care 2011;39(6):1103-1110.

56. Mauri T, Alban L, Turrini C, Cambiaghi B, Carlesso E, Taccone P, et al. Optimum support by high-flow nasal cannula in acute hypoxemic respiratory failure: effects of increasing flow rates. Intensive Care Med 2017;43(10):1453-1463.

57. Roca O, Messika J, Caralt B, García-de-Acilu M, Sztrymf B, Ricard JD, Masclans JR. Predicting success of high-flow nasal cannula in pneumonia patients with hypoxemic respiratory failure: the utility of the rox index. J Crit Care 2016;35:200-205.

58. Roca O, Caralt B, Messika J, Samper M, Sztrymf B, Hernández G, et al. An index combining respiratory rate and oxygenation to predict outcome of nasal high-flow therapy. Am J Respir Crit Care Med 2019;199(11):1368-1376.

59. Zemach S, Helviz Y, Shitrit M, Friedman R, Levin PD. The use of high-flow nasal cannula oxygen outside the ICU. Respir Care 2019;64 (11):1333-1342
60. Rodriguez M, Thille AW, Boissier F, Veinstein A, Chatellier D, Robert R, et al. Predictors of successful separation from high-flow nasal oxygen therapy in patients with acute respiratory failure: a retrospective monocenter study. Ann Intensive Care 2019;9(1):101.

61. Mauri T, Carlesso E, Spinelli E, Turrini C, Corte FD, Russo R, et al. Increasing support by nasal high flow acutely modifies the rox index in hypoxemic patients: a physiologic study. J Crit Care 2019;53:183185.

62. Duprez F, Bruyneel A, Machayekhi S, Droguet M, Bouckaert Y, Brimioulle $\mathrm{S}$, et al. The double-trunk mask improves oxygenation during high-flow nasal cannula therapy for acute hypoxemic respiratory failure. Respir Care 2019;64(8):908-914.

63. Bennett G, Joyce M, Fernández EF, MacLoughlin R. Comparison of aerosol delivery across combinations of drug delivery interfaces with and without concurrent high-flow nasal therapy. Intensive Care Med Exp 2019;7(1):20.

64. Dugernier J, Reychler G, Vecellio L, Ehrmann S. Nasal high-flow nebulization for lung drug delivery: theoretical, experimental, and clinical application. J Aerosol Med Pulm Drug Deliv 2019;32(6):341-351.

65. Levy SD, Alladina JW, Hibbert KA, Harris RS, Bajwa EK, Hess DR. High-flow oxygen therapy and other inhaled therapies in intensive care units. Lancet 2016;387(10030):1867-1878.

66. Li J, Zhao M, Hadeer M, Luo J, Fink JB. Dose response to transnasal pulmonary administration of bronchodilator aerosols via nasal highflow therapy in adults with stable chronic obstructive pulmonary disease and asthma. Respiration 2019;98(5):401-409.

67. Baudin F, Buisson A, Vanel B, Massenavette B, Pouyau R, Javouhey E. Nasal high flow in management of children with status asthmaticus: a retrospective observational study. Ann Intensive Care 2017;7(1):55.

68. Li J, Harnois LJ, Markos B, Roberts KM, Homoud SA, Liu J, et al. Epoprostenol delivered via high flow nasal cannula for ICU subjects with severe hypoxemia comorbid with pulmonary hypertension or right heart dysfunction. Pharmaceutics 2019;11(6):281.

69. Ammar MA, Sasidhar M, Lam SW. Inhaled epoprostenol through noninvasive routes of ventilator support systems. Ann Pharmacother 2018;52(12):1173-1181.

70. Li J, Gurnani PK, Roberts KM, Fink JB, Vines D. The clinical impact of flow titration on epoprostenol delivery via high flow nasal cannula for ICU patients with pulmonary hypertension or right ventricular dysfunction: a retrospective cohort comparison study. J Clin Med 2020;9 (2):464. 